\title{
Identidade na Educação de Jovens e Adultos através da integração do Teatro, Música e Cultura Digital ${ }^{1}$
}

\author{
Clevi Rapkiewicz ${ }^{1}$, Lisinei Dieguez Rodrigues ${ }^{1}$, Daniela Cesa Fracasso ${ }^{1}$, Guilherme \\ Weihmann ${ }^{1}$
}

\author{
${ }^{1}$ Colégio de Aplicação - Universidade Federal do Rio Grande do Sul (UFRGS) \\ clevi@ufrgs.br, lisinei@cap.ufrgs.br, dani_fracasso@yahoo.com.br , \\ grweihmannegmail.com
}

\begin{abstract}
Digital inclusion and collaborative teaching have worked as integrated actions among the curricular components of Expression and Movement (theater, music, and physical education) at UFRGS Application College. At this stage of the work we analyze the aspects of self-recognition and self-worth of the identity of students of the Youth and Adult Education (EJA) from thinkers in the fields of Art, Pedagogy and Informatics. The record of practical experiements in the areas of knowledge involved enabled the insertion of Informatics as an ally in the identity recovery process of the students and created conditions for studies ever conducted to approach what we still want to investigate in the field of digital inclusion for EJA students
\end{abstract}

Keywords: ICT; Digital Inclusion; Theater; Music

Resumo: A inclusão digital e a docência compartilhada têm constituído ações integradas entre os componentes curriculares de Expressão e Movimento (Teatro, Música, e Educação Física) no Colégio de Aplicação da UFRGS. Nesta etapa do trabalho analisa-se os aspectos do reconhecimento de si e da autovalorização da identidade dos estudantes da Educação de Jovens e Adultos (EJA) a partir de pensadores das áreas da Arte, da Pedagogia e da Informática. $O$ registro das experiências práticas nas áreas de conhecimento envolvidas possibilitaram a inserção da Informática como aliada no processo da valorização identitária dos alunos e oportunizaram a aproximação dos estudos já realizado ao que ainda deseja-se investigar no campo da inclusão digital para alunos da EJA.

Palavras-Chave: TIC; EJA; Inclusão Digital; Teatro; Música

\section{Introdução}

O Colégio de Aplicação da UFRGS (CAP UFRGS) oferece Educação de Jovens e Adultos (EJA), nível ensino médio, à noite, organizado em três semestres. Trata-se de um projeto integrado, interdisciplinar, no qual as disciplinas não são estudadas de forma isolada, mas sim formando teias de saberes dentro de um mesmo componente curricular. Por esse motivo, o curso estrutura-se em quatro blocos de conhecimentos

\footnotetext{
${ }^{1}$ Agradecimento a Cristiani de Oliveira Dias pelos esclarecimentos do modelo de inclusão digital de Warschauer e a Valéria Machado da Costa (FIOCRUZ) pela indicação do ciclo de atividades proposto no modelo de Prain e Hand (1996). A inclusão desses dois autores no referencial teórico do projeto permitiu melhor integração da Cultura Digital com os componentes curriculares da área artística.
}

Proceedings of the XII SIBGRAPI (October 1999) 101-104

DOI: 10.5753/cbie.wie.2015.11 
assim organizados: Exatas e da Natureza, Humanidades, Linguagens, Expressão e Movimento. A Cultura Digital no contexto do bloco Expressão e Movimento atua como elemento integrador entre os demais componentes curriculares (Música, Teatro, Educação Física) de forma a capacitar os alunos a usar recursos de Tecnologias de Informação e Comunicação (TICs) para se expressarem através de diferentes formas de registro: personagens na forma de avatar ou de fotografias editadas, apresentações presenciais e virtuais, vídeo (reaproveitando outros ou desenvolvendo seus próprios), sons, entre outras.

Então, como abordar metodologicamente uma forma de expressão constitutiva da própria natureza do ser humano, mas que, para caracterizar-se como forma artística, necessita percorrer um caminho de aprendizagem ética e estética? Como envolver os estudantes nessa aprendizagem cercada de padrões culturais e convenções artísticas? As ações pedagógicas em curso partiram da crença de que a perspectiva interdisciplinar ao invés de menosprezar a relevância dos campos especializados do conhecimento, possa por contraste ou complementação, incrementar uma leitura de mundo mais ampla.

A importância das disciplinas, segundo Fazenda (2008), está nas suas especificidades e mais do que forçar uma integração é necessário educar o olhar do professor para a totalidade de conhecimentos que a articulação pode engendrar. Diante do desafio de desenvolver propostas curriculares para a EJA, a interdisciplinaridade aparece como metodologia capaz de dar conta dos exíguos tempos que os estudantes possuem para dedicação escolar e ainda potencializar seus saberes prévios.

No plano de ensino da EJA do CAP - UFRGS, as disciplinas propõem o exercício do olhar crítico a partir dos seus materiais específicos, atentos para o fato de que os estudantes retornam para a escola com valores éticos e estéticos que, por vezes podem vir de encontro aos saberes academicamente desejados.

Ao objetivar a ampliação da ideia da aula de Teatro como uma prática em educação condizente com os tempos e espaços de adultos e jovens reincluídos no contexto escolar, a oferta da educação estética oportuniza a participação social e cultural de forma crítica, criadora e autônoma.

A Arte representa uma forma de pensar e uma forma de saber que tem por base, e por fim, a expressão. Na perspectiva da educação em arte, considera-se que é nos momentos de produção individual, em que o aluno cria, expondo suas próprias ideias, que ele trabalha a autenticidade e a autonomia. Estendendo esses momentos para as atividades de caráter coletivo, agregam-se as possibilidades de articular ação e reflexão acerca de seus próprios processos cognitivos, bem como os de seus colegas. São essas propostas teóricas-práticas de ação e de reflexão sobre a ação que auxiliam os estudantes quanto à sua organização pessoal, social e espacial. A arte constitui, ainda, a expressão do que não pode ser explicitado por outras formas de representação, buscando desenvolver o autoconhecimento, o conhecimento do outro e suas relações com o mundo.

A apreciação e o senso crítico são exercitados tanto na análise de diferentes manifestações artísticas quanto nas leituras e debates sobre a produção individual e coletiva dos próprios alunos e de artistas renomados, auxiliando-os a conhecer e respeitar as diversidades culturais, alicerçados nos valores e princípios éticos da solidariedade, participação, cooperação, respeito a si e ao outro, à natureza e ao espaço físico. 
As intervenções pedagógicas levam em conta os aspectos da estética e da ética que podem ser contemplados a partir da prática em atividades de caráter comunal e socializante. As possibilidades de articulação entre as diversas áreas do conhecimento que compõem o bloco de Expressão e Movimento, ainda podem favorecer a compreensão de noções dos estudos da corporeidade e suas manifestações como produtores de discursos e fomentadores de leituras de mundo. O bloco busca trabalhar de forma ampla os conceitos referentes a cada área, visto que se propõe a trabalhar em projetos interdisciplinares com a finalidade de relacionar diferentes formas de linguagem. Porém, há também a necessidade de trabalhar conhecimentos específicos de cada área, com o cuidado de inseri-los dentro do contexto do projeto.

$\mathrm{Na}$ instituição na qual esse trabalho desenvolve-se o ingresso dos estudantes ocorre através de Edital de Sorteio Público. Tanto nas observações empíricas como nas análises de outros contextos disponíveis na literatura especializada, é possível constatar que o ingresso de jovens e adultos na escolarização formal em uma instituição pública é, por vezes, atravessado de tensões que variam desde dificuldades econômicas para manter-se no curso até a baixa-estima no que se refere às condições individuais para o ato de aprender.

Por esse motivo, a "identidade" como conceito, através do reconhecimento de si e da autovalorização, coloca-se como necessária nos planos de ensino dos componentes curriculares.

Desde que a EJA configurou-se como uma política afirmativa de direitos, que visa atender eficientemente seu público diferenciado, percebemos ainda mais os esforços de seus educadores, em geral, para a realização de práticas pedagógicas contextualizadas, que se relacionem com as diversas trajetórias de seus alunos, com a realidade em que vivem e com suas demandas particulares. Tal evidência caracteriza a EJA como uma das modalidades de ensino que parte, de fato, da multiplicidade cotidiana para o trabalho em sala de aula. (CURTO, 2009, p.2)

De fato, a identidade e a contextualização estão diretamente relacionadas na medida em que a construção da identidade está relacionada com o meio social no qual o sujeito está inserido. Cavalheiro (2000) enfatiza que a identidade em última instância resulta da visão que temos de nós mesmos. Já Silva (2000) afirma que identidade é aquilo que se é enquanto diferença é aquilo que o outro é.

Neste artigo apresentamos as formas como buscamos trabalhar aspectos da identidade dos estudantes da EJA a partir do resgate de memórias relacionadas a Arte (particularmente o Teatro e a Música) e a Educação Física Para isso, o artigo está organizado em 4 seções além da presente introdução. Na seção 2 apresentamos uma síntese do referencial teórico que orientou as práticas pedagógicas integradas costurado com a apresentação das próprias práticas, ao invés de separarmos uma seção de referencial teórico e outra de metodologia. Acreditamos que essa escrita integrada é mais condizente com a proposta desenvolvida e, também, facilita a compreensão do leitor. $\mathrm{Na}$ seção 3 apresentamos a análise dos resultados e na seção 4 algumas considerações finais. 


\title{
2. Costurando referencial teórico e práticas pedagógicas
}

O referencial teórico está organizado em diferentes eixos, considerando os diferentes componentes curriculares envolvidos nas práticas integradas.

No que concerne ao Teatro, buscamos trabalhar questões relacionadas ao corpo, o que permite que outras questões como gênero e sexualidade, pluralidade cultural e condições socioeconômicas também emerjam diante da apreciação de cada uma das atividades teatrais desenvolvidas, legitimando a presença do corpo-artista como autorleitor de subjetividades já que

\begin{abstract}
Quando o aluno vê as pessoas e as maneiras como elas se comportam quando juntas, quando vê a cor do céu, ouve os sons do ar, sente o chão sob seus pés e o vento em sua face, ele adquire uma visão mais ampla de seu mundo [...] (SPOLIN, 1987, p.13)
\end{abstract}

O trabalho corporal desenvolvido nas aulas de Teatro objetivou a contemplação de uma autodescrição como indivíduo, da apreciação da autodescrição dos colegas e, por fim, de uma descrição coletiva do que aquele grupo de estudantes da turma EM2 ${ }^{2}$ podia identificar como semelhante ou diferente.

A proposta do estudo da identidade foi contemplada a partir do resgate de memórias relacionadas a apreciação de espetáculos anteriores ao ingresso na EJA, atividades práticas de improvisação teatral e de expressão corporal com temáticas que subsidiassem a representação de situações envolvendo movimentações cotidianas.

Atividades de criação de movimentos corporais a partir de músicas trazidas pela professora ou pelos estudantes; composição de cenas teatrais envolvendo figurinos que remetiam a tempos passados ou ainda a situações do cotidiano tais como, comer, escrever, cantar, trabalhar, dançar, utilizar transportes.

O grupo assistiu a espetáculos teatrais de profissionais na cidade de Porto Alegre. Um dos espetáculos trazia a temática da escravização dos negros no Brasil. Por esse motivo, tal atividade também contemplou uma parceria com a disciplina de História. Uma das produções artísticas desenvolvidas posteriormente a apreciação desse espetáculo trouxe um grupo de nove adultos e jovens utilizando como narrativa a expressão corporal. Esse grupo mostrava um casal de brancos utilizando uma carroça construída com tiras de elásticos. O signo teatral era completado com a presença de seis colegas negros representando a dor dos açoites e a humilhação infligida pela escravidão.

A imagem artística de uma situação trabalhada em outros contextos foi contundente no sentido de motivar o grupo a ousar mais em relação ao trabalho expressivo e na própria participação na vida escolar proporcionada pela EJA. Tal reverberação pode ser explicada a partir da Pedagogia do Oprimido explicada em Desgranges, 2003 p. 45:

Os grupos buscavam a utilização do palco como espaço para a discussão de questões que afligiam nossas sociedades. Convidando os espectadores a participarem desses debates. (...) e provocar a atitude do público diante dos fatos trazidos à cena.

\footnotetext{
${ }^{2}$ Correspondente ao segundo ano do Ensino Médio.
} 
No que concerne a Música, há que se considerar que ela apresenta por si só uma diversidade quase incontável de manifestações que são levadas para dentro da sala de aula pelos alunos. Uma das preocupações, no contexto da EJA no CAP UFRGS é, justamente, valorizar essa diversidade na busca do reconhecimento das vivências musicais dos alunos. Ribas (2009, p.132) destaca que "embora o interesse acerca da música seja comum aos/às estudantes [da EJA], [...] eles/as têm diversos modos de lidar com a música e isso gera graus variáveis de tensionamentos e conflitos" (RIBAS, 2009, p.132). Isso se dá ao fato de que encontramos na sala de aula alunos de contexto sociais e culturais distintos e de idades igualmente variadas. Essa mesma autora traz, como resultado de sua pesquisa que, "na escola, essas pessoas buscam ter experiências educativas onde o espaço da música nas aulas [...] sejam espaços de apropriação $e$ transmissão de conhecimentos musicais".

No contexto específico da EJA da escola onde ocorreu a integração, o componente curricular Música encontrou no projeto de ensino proposto uma oportunidade para se trabalhar com essas diversidades de experiências, vivências e expectativas com vistas ao ensino e aprendizagem de conhecimentos musicais. Ao encontro das propostas curriculares para EJA, a ideia de trabalhar a Música com os alunos do $1^{\circ}$ ano do Ensino Médio buscou "proporcionar [...] momentos significativos de expressão pessoal, autoconhecimento, conhecimento do mundo e o aumento da autoestima", além do reconhecimento do outro (BRASIL,2002, p. 163).

A atividade proposta pela Música teve como motivação inicial o texto "Infância, canção popular e educação", publicado por Ricardo Azevedo na Revista Emília. Nesse texto o autor refaz sua trajetória de vida contada através de canções que foram significativas para seu desenvolvimento pessoal (AZEVEDO, 2012). A proposta foi a de que a partir do reconhecimento da identidade musical do outro, os alunos pensassem sobre sua identidade musical e de que forma a música esteve/está presente nas suas vidas. Ou ainda, de que forma a música participou/participa da construção da sua identidade. Além disso, o trabalho buscava um resgate da memória, uma vez que muitos alunos já tinham uma longa trajetória de vida.

Os alunos foram convidados a realizar uma leitura do texto, seguida de um debate sobre as compreensões dessa leitura. Após esse debate, nos encontros que se seguiram, cada estudante teve como tarefa recuperar canções que foram significativas nas suas vidas, que os representassem ou identificassem. Com o objetivo de trabalhar também questões da escrita e construção textual os alunos deveriam construir, para cada uma das canções escolhidas, justificativas contando as razões pelas quais aquelas músicas faziam parte de um repertório que os identificava, de um repertório que falava sobre suas trajetórias. De um repertório que lhe permitia resgatar memória musical.

A Cultura Digital entrou de forma significativa para o desenvolvimento dessa atividade. Isso permitiu trabalhar a ideia de inclusão digital para além do acesso as TIC (o que ocorreu para muitos praticamente pela primeira vez), primeiro nível de inclusão apontado por Warschauer (2006) e intitulado pelo autor como letrado digitalmente (por meio de computador), ou seja, o sujeito que domina comandos simples no computador como ligar e desligar o computador, salvar arquivo, criar uma pasta. A atividade de buscar as músicas via pesquisa na Internet e registrar as memórias musicais em edição de texto permitiu alcançar o segundo nível de inclusão, apontado por Warschauer (2006) como o letrado Informacional, qual seja, aquele que executa ações de localizar, selecionar, acessar e organizar e usar informações afim de gerar 
conhecimento, visando tomada de decisão e à resolução de problemas. O problema em questão era primeiro o resgate das memórias, depois a localização dos componentes musicais dessas memórias, para, finalmente, fazer o registro digital por meio de edição de textos.

Após um primeiro resgate de memória das músicas, era fundamental que os alunos pudessem escutar o repertório escolhido, de forma a experimentarem sensações e revisitarem os momentos/lugares/contextos nos quais aquelas músicas estiveram presentes através do contato com o material sonoro. Desse modo, com o auxilio da professora e equipe de Informática, trabalhada na EJA como Cultura Digital, os alunos tiveram a oportunidade de visitar espaços virtuais onde pudessem escutar as canções que haviam selecionado. Essa atividade propiciou o desenvolvimento de competências de pesquisa na Internet de forma contextualizada: a busca de saberes relacionados as memórias dos alunos, não pesquisa mecânica sobre temas aleatórios sem nexo com a realidade vivida por eles. Em seguida, o registro dessas memórias foi feito através de digitação usando editor de texto, propiciando o desenvolvimento de uma nova competência: a autoria textual individual usando texto de produção própria.

A proposta tinha, para além da construção da sua identidade musical, o objetivo de que pudéssemos conhecer a identidade musical do outro e perceber a identidade musical do grupo. Para compartilhar as trajetórias de cada um, o uso de editor de apresentação mostrou-se uma ferramenta adequada, uma vez que os alunos, com o auxilio da equipe de Cultura Digital, puderam construir uma apresentação onde juntavam os textos explicativos com os links das canções escolhidas, congregando assim texto escrito, visual e sonoro. Buscamos, dessa forma, atingir o terceiro nível de inclusão apontado por Warschauer (2006), o letrado em Multimídia, qual seja, o que consegue identificar representações informações iconográfica ou multimodal. Mais que isso, os alunos conseguiram construir representações iconográficas de suas memórias integrando texto, imagem e som.

\section{Análise dos resultados}

Apresentamos, a seguir, pequenos recortes de textos das memórias produzidas pelos alunos. Na Figura 1 pode ser observar que há indicação sobretudo de bandas, sem menção de músicas específicas. A produção textual é feita de maneira desestruturada, mais próxima de um relato oral do que de um texto escrito. Já na Figura 2 há a estruturação em subseções, delimitando em momentos distintos da trajetória do aluno. Há boa exploração do recurso de edição de texto com diferenciação de cores, de grifos (itálico e negrito), bem como registro de resgate das pesquisas feitas através da indicação de links. 
CBIE-LACLO 2015

Anais do XXI Workshop de Informática na Escola (WIE 2015)

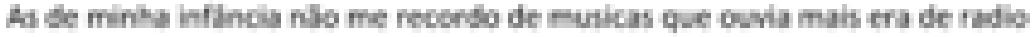

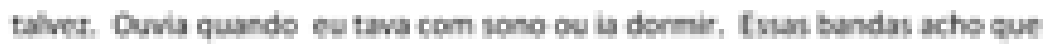

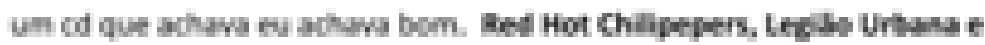 \\ Bint.

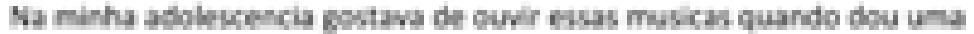

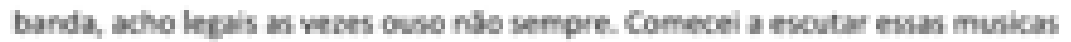

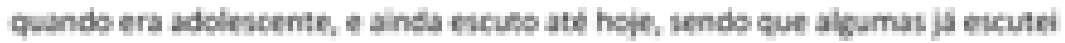

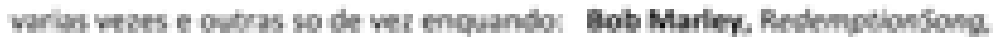

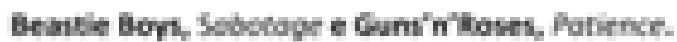

Figura 1: Texto das memórias resgatadas pelo aluno 1

\title{
Infância :
}

Estas músicas, Uni duni te (http://www.youtube.com/watch?v=tUQ2yLP7RHI) e é de Chocolate (http://www.youtube.com/watch?v=YZt3mlybROY) do grupo Trem da Alegria me remetem imediatamente às festinhas infantis de coleguinhas, irmãos e primos... Não tinha coisa melhor para mim do que estas festinhas, eram simplesmente os melhores momentos e melhores lembranças.

\section{Adolescência}

Estas duas músicas de Cássia Eller e Gabriel o Pensador,_Malandragem (http://www.youtube.com/watch?v=UkGF4RdxrWs)e Cachimbo da Paz (http://www.youtube.com/watch?v=bcPLI-Ty1fE) me marcaram pela letra simples, fácil de ser cantada, e era top na minha adolescência, resumindo eu cantava muito, o tempo todo... Aquela música que fica na cabeça, que tocava na escola, e nas reuniões com as colegas, e tem certa identidade com esta fase.

\section{Adulta}

Estas músicas que compõe o álbum Once, When your mind's made up, If you want

Figura 2: Trecho do texto das memórias resgatadas pelo aluno 2

Já na Figura 3 podemos perceber o estrato de um texto completamente estruturado, com justificativas de significados dos resgates feitos e exploração mais avançada dos recursos de edição de texto. $\mathrm{O}$ aluno em questão optou por não colocar na sua produção textual os links das pesquisas feitas, deixando indicações mais gerais dos artistas que estiveram presentes na sua linha do tempo musical. Mas na exploração do editor de apresentações apresentou com desenvoltura os links. 
CBIE-LACLO 2015

Anais do XXI Workshop de Informática na Escola (WIE 2015)

\footnotetext{
Já na minha juventude foram muitas musicas da RPM como a Alvorada Voraz, Biquíni de Bolinha Amarelinha, Menina do Baile de Os Atuais, Vou de Táxi da Angélica, Não Aprendi Dizer Adeus e muito mais. Foi uma época muito boa, de muita felicidade. Nesta época comecei a sair para dançar, passear e a conhecer o mundo, me lembro também que comecei a conhecer muitas músicas gaúchas e sertanejas, Gaúcho da Fronteira, Chitãozinho e Chororó, Zezé de Camargo e Luciano e também Almir Sater com a música Chalana.

Porém na vida adulta já foi muitas melodias diferentes desde o Hino RioGrandense, Ai se Eu te Pego e Domingo de Manhã e porque não Anita com As Poderosas, e assim foi minha vida, estas musicas e melodias vem dês da década de 70, 80 e me acompanha até os dias de hoje. E também o CTG e os piquetes com muitas musicas gauchas, como Do Fundo da Grota com Baitaca e foi muitos bailes e festas nos CTGS e no Parque da Harmonia. Sempre que pude também trabalhava escutando musicas como Baila Morena, Festa no Apê com Latino e assim fui vivendo e escutando musicas das mais variadas desde o Rock ao Vanerão, e porque não um Samba com Harmonia do Samba.

Assim é a história da minha vida contada pelas músicas, mas espero que outras muitas músicas lindas e marcantes surjam na minha vida até a minha morte.
}

Figura 3: Trecho do texto das memórias resgatadas pelo aluno 3

No início do semestre letivo seguinte, os alunos apresentaram suas memórias para os alunos recém entrantes. Isso permitiu que a segunda turma com quem o projeto foi desenvolvido tivesse uma visão do 'produto' final da integração das disciplinas, que foi uma das dificuldades encontradas na primeira edição dessa integração dos componentes curriculares de Expressão e Movimento. Observar que nesse ciclo de produção ao invés do aluno desenvolver algo meramente para ser lido e corrigido pelo professor, foram completados os cinco elementos do modelo proposto por de Prain e Hand (1996): tópico (tema central) [aqui proposto pela equipe docente], b) tipo (gênero do texto) - a memória na forma de linha do tempo de suas vivências musicais e artísticas num texto linear escrito e um texto iconográfico com figuras, áudio, imagem e texto integrados num editor de apresentações, c) audiência (para quem se fala) - para colegas do semestre seguinte, d) método de produção textual (tecnologia utilizada para a produção do texto) -editores de texto e de apresentação e) objetivo (o que se deseja com o texto) - resgate da identidade de si e visão da identidade do outro a partir do resgate das memórias musicais e artísticas.

Os depoimentos, espontâneos, tanto por parte da plateia (os alunos novos) quanto por parte dos apresentadores (os alunos que participaram do projeto no semestre anterior) mostrou que a interdisciplinaridade entre Música, Teatro e Cultura Digital produziu significados para a maioria dos alunos. O exercício da autoria linear textual e não linear na edição de uma apresentação permitiu o desenvolvimento de competências nos três primeiros níveis de letramento digital mencionados por Warschauer (2006). Em certa medida também foi atingido o quarto nível, qual seja, letrado comunicacional no qual o sujeito tem habilidade de se comunicar efetivamente por meio de mídias, dominar linguagem apropriada e ter interação com ferramentas comunicacionais síncronas e assíncronas. Dizemos em certa medida porque houve comunicação mediada por um recurso tecnológico (arquivo com a apresentação) usando projetor multimídia. A interação com ferramentas comunicacionais síncronas e assíncronas poderia ser alcançada com a publicação das produções em um grupo numa 
rede social ou numa plataforma tipo o Moodle, promovendo troca de ideias entre os alunos. Essa ideia fica para uma próxima implementação do projeto.

\section{Considerações finais}

A integração dos componentes curriculares Música, Teatro e Cultura Digital mostrou-se muito rico e significativo tanto para os professores envolvidos quanto para os alunos. Para os professores de Teatro e Música significou a compreensão dos limites e possibilidades do uso de recursos de TIC nessas disciplinas, ainda que de forma pontual como a produção textual e de apresentações. A proposta de continuidade para os alunos é que elementos da tecnologia per se sejam integrados nas práticas artísticas, como editores de áudio para construção de paisagens sonoras e construção de personagens virtuais para interagir com personagens teatrais nas montagens cênicas.

Para os alunos significou a apropriação de recursos básicos de TIC através de atividades contextualizadas, nas quais a tecnologia foi um instrumento de mediação (Vygostky, 1991) para o desenvolvimento do letramento digital, não sendo o aprendizado da tecnologia o objetivo em si das atividades. Mas esse aprendizado ocorreu de forma incidental. Não foram poucos os alunos que a partir do uso do editor de texto, por exemplo, solicitaram auxílio a equipe de Informática para desenvolver seus currículos para buscar melhores empregos.

Há que ressaltar as múltiplas dificuldades associadas a este projeto. Uma delas diz respeito ao alto índice de absenteísmo que ocorre na EJA. Como se trata de um trabalho contínuo, a ausência dos alunos em várias aulas 'quebra' a sequência de atividades. Infelizmente os que mais faltam geralmente são os que têm mais dificuldade, caracterizando um ciclo vicioso que dificulta o resgate. A precariedade dos empregos que eles têm (quando tem), o transporte público de baixa qualidade e irregular em suas frequências que promove atrasos e cansaço adicional ao dia de trabalho do aluno-trabalhador que (ainda) tenta se manter nos bancos escolares.

A infraestrutura que a escola dispõe também desafia o professor no sentido de alcançar a motivação necessária para esses estudantes-trabalhadores. A quantidade de computadores do laboratório é insuficiente para atender a turma toda numa relação de um para um (um computador por aluno). O estado de conservação dos móveis e a falta de um planejamento ergonômico para o mobiliário e para as condições de ventilação e iluminância da sala, configuram mais um entrave para o bom acolhimentos. Elementos essenciais para as atividades, como os fones de ouvidos, são improvisados e acabam por prejudicar a qualidade das produções sonoras desenvolvidas pelos estudantes, contribuindo como um fator de desmobilização para as atividades.

Mais do que a constatação das dificuldades de recursos, preocupa o fato de que apesar de todos os esforços no sentido de garantir uma educação pública de qualidade e conectada com os desafios da sociedade contemporânea, os estudantes ainda tenham pouco reconhecimento de suas necessidades de acolhimento. 


\section{Referências}

AZEVEDO, Ricardo. Infância, canção popular e educação. Revista Emília, 2012. Disponível em <http://www.revistaemilia.com.br/mostra.php?id=264> acesso em mar 2015.

BRASIL. Ministério da Educação. Secretaria de educação fundamental. Proposta curricular para a educação de jovens e adultos: segundo segmento do ensino fundamental, $5^{\text {a }}$ a $8^{\text {a }}$ séries. V.3Artes, p. 135-189. Brasília, 2002. Disponível em <http://portal.mec.gov.br/secad/arquivos/pdf/eja/propostacurricular/segundosegmento/v ol3_arte.pdf> acesso em: maio 2015.

BRASIL. Secretaria de Educação Fundamental. Parâmetros Curriculares Nacionais: Arte. Brasília: MEC/SEF, 1996.

CAVALHEIRO, E. Do silêncio do lar ao silêncio escolar. São Paulo, Contexto, 2000.

CURTO, Viviane. Trabalhando com o computador na EJA: uma análise dos relatos das práticas pedagógicas em meio digital com jovens e adultos. Belo Horizonte: 2009.

DESGRANGES, Flavio. A Pedagogia do Espectador. São Paulo: Hucitec, 2003.

FAZENDA, Ivani C. A. Interdisciplinaridade e transdisciplinaridade na formação de professores. Revista do Centro de Educação e Letras. UNIOESTE - Campus Foz do Iguaçu. v. 10 - $\mathrm{n}^{\mathrm{o}} 1$ - $1^{\mathrm{o}} \mathrm{sem}, 2008$. P. 93-103.

PRAIN, Vaugh; HAND, Brian. Writing and learning in secondary science: Rethinking practices. Teacher and Teacher Education. n. 12, 1996, pp. 609-626.

RIBAS, Maria Guiomar de Carvalho. Práticas musicais na Educação de Jovens e Adultos: uma abordagem geracional. Revista da ABEM, Porto Alegre, V. 21, 124-134, mar. 2009.

SILVA, T. T. A produção social da identidade. In: Identidade e diferença. Rio de Janeiro, Editora Vozes, 2000.

SPOLIN,Viola. Improvisação para teatro. São Paulo: Perspectiva, 1979.

VYGOTSKY, Lev. S. O instrumento e o símbolo no desenvolvimento da criança. In: A formação social da mente: o desenvolvimento dos processos psicológicos superiores. 4. ed. São Paulo: Martins Fontes, 1991.

WARSCHAUER, Mark. Tecnologia e Inclusão Social: a exclusão digital em debate. São Paulo: Editora SENAC, 2006 